\title{
PATRIMONIO, ANTROPOLOGÍA Y CAZA. Experimentos pedagógicos en un aula de la UGR
}

\author{
Ester MASSÓ GUIJARRO; Pablo MONDRAGóN VALERO; Ana SANTÁNGELO \\ Universidad de Granada (España) \\ ester@ugr.es
}

\begin{abstract}
heritage, ANThropology AND HUNTING. Pedagogic experiment in a classroom at the University of Granada
\end{abstract}

Resumen: El patrimonio constituye una noción que ha hecho indudable fortuna, tanto en múltiples disciplinas como el mundo de la vida y distintas esferas sociales. Cierto que las virtudes de la institucionalización y la globalización del concepto de patrimonio son innegables en diversas escalas; sin embargo, su problematicidad epistemológica en el terreno antropológico le ha acompañado desde sus primeras formulaciones. Con esta visión crítica de fondo, se propuso en un aula universitaria la realización de una práctica sobre caza y patrimonialización, durante la que el alumnado coautor de este trabajo desarrolló una forma alternativa de presentación de un material didáctico, que supone una clara innovación en la enseñanza universitaria sobre patrimonio: se pretendió acercar al alumnado el tema de una forma dinámica, basada en los métodos de la pedagogía teatral, como pretexto para una discusión antropológica vinculada a los procesos de patrimonialización inmaterial contemporáneos.

Abstract: Heritage has become an undoubtedly fortunate notion, both in multiple disciplines and the world of life or different social spheres, by plural reasons. Virtues and advantages of the heritage institutionalization and globalization are undeniable at various scales. Yet, it is also true that its epistemological problematical in anthropological field has followed heritage from its early roads and formulations. On this critical perspective, a practice on hunting and heritage (obvious topic of social controversy, including ethics) was proposed in a classroom at college, in order to reflect key questions raised from an anthropological (decolonial) perspective. So with hunting as notorious case, (coauthor of this paper) students developed an alternative way of presenting didactic material, which is a clear innovation in university education on anthropological heritage.

Palabras clave: Antropología. Patrimonio. Estudios Poscoloniales. Pedagogía Teatral. Innovación Docente Anthropology. Heritage. Poscolonial Studies. Theatre Pedagogy. Teaching Innovation 


\title{
1. Introducción: ¿antropología, caza, patrimonio ${ }^{1} \ldots$ ?
}

\begin{abstract}
"Este Viaje a Portugal es una historia. Historia de un viajero en el interior del viaje que hizo, historia de un viaje que en sí transportó a un viajero, historia de viajero y viaje reunidos en una intencionada fusión de aquel que ve y de aquello que es visto, encuentro no siempre pacífico de subjetividades y objetividades. En consecuencia: choque y adecuación, reconocimiento y descubierta, confirmación y sorpresa" (Saramago, 2004: 5).
\end{abstract}

Este artículo nace tras la experiencia de pedagogías alternativas en la presentación de materiales didácticos practicada en aula durante la docencia de la asignatura obligatoria "Patrimonio y Gestión Cultural", de $2^{\circ}$ curso en el Grado de Antropología Social de la Universidad de Granada (España). Se presenta como trabajo colectivo de la comunidad docente que suponen una asignatura y un aula en la universidad, a saber: elaborado conjuntamente por dos personas miembros del alumnado y por una persona miembro del profesorado. Así, ya desde lo metodológico, se pretende mostrar una forma de etnografía colaborativa de creciente predicamento en la disciplina antropológica ${ }^{2}$, que deseamos conjugar aquí con el campo patrimonial y, específicamente, el patrimonio inmaterial, que supone acaso el "más antropológico" de los patrimonios (y a su vez el más susceptible de problematización etnológica).

El patrimonio constituye una noción que ha hecho indudable fortuna, tanto en múltiples disciplinas como el mundo de la vida y distintas esferas sociales, por razones diversas. Algunas de ellas, acaso las cruciales, residen en que este concepto confluye enormemente con las melodías filosóficas propias de las tendencias globalizadoras actuales: derechos humanos y colectivos, institucionalización a grandes escalas, garantías de calidad, códigos deontológicos, etc. Supone, en fin, una cristalización de anhelos y símbolos en algo tan concreto, tangible, mensurable, universalizable, como la UNESCO o el ICOM, el Consejo de Patrimonio Histórico español en el caso nacional o el IAPH en el contexto autonómico andaluz.

Cierto que las virtudes y ventajas de la institucionalización y la globalización del concepto de patrimonio son innegables en múltiples escalas. Sin embargo, tan veraz resulta que su problematicidad epistemológica en el terreno antropológico le ha acompañado desde sus primeros caminos y formulaciones ${ }^{3}$. El patrimonio, como condensación identitaria que implica, en su inexorable vocación de salvaguardia, un estatismo consustancial a cualquier institucionalización, se da de bruces con las teorías más depuradas sobre lo escurridizo, móvil y especular de los mismos conceptos de identidad o cultural. Parece existir una aporía antropológica irresoluble en el patrimonio, tanto o incluso más aún en su supuesta versión más etnológica, a saber, el patrimonio inmaterial: ¿por qué y para qué patrimonializar la vida cultural, en definitiva? Si añadimos las discusiones críticas en torno al eje, axial para el patrimonio, del turismo, nos hallamos en una tesitura con difícil solución.

Pero, si el patrimonio es, en última instancia, el cuento que una cultura se cuenta sobre sí misma (el murmullo infinito de un pueblo, que diría Saramago -2004: 5-), y más aún, la institucionalización de ese cuento... ¿qué sentido tiene patrimonializar oficialmente? ¿No subyace una aporía esencial de base a la misma de idea de patrimonializar, por más que la

\footnotetext{
1 Una versión reducida del presente artículo fue presentada a modo de comunicación en el I Congreso Internacional de Patrimonio y Educación, celebrado en la Universidad de Granada (España), del 22 al 24 de mayo de 2014.

2 Ver por ejemplo http://network2matter.net/2014/04/28/antropocefa-kit-para-la-fabricacion-de-colaboraciones-etnograficas-experimentales/ (fecha de acceso: 29/04/2014).

3Ver por ejemplo, Prats 2004, Choay 2009, González Alcantud 2003 y 2012.
} 
liberemos, la descolonicemos...? ¿No se trata de patriarcalizar-o patrocinar- el sentido de los actos, objetos e intervenciones colectivos, en tanto que otorgarles una pátina de inamovilidad y, así, escamoteárselos al pueblo, desde lo más material hasta lo más simbólico, y ambos entrecruzados? (¿hasta qué punto patrimonio y patriarcado no comparten algo más que mera coincidencia etimológica?).

Con estos y otros interrogantes, planteamientos epistémicos de fondo (con más preguntas osadas que respuestas definitivas), se propuso en aula la realización de una práctica sobre caza y patrimonialización (cuestión de obvia controversia social, ética incluso), tratando de reflejar en la misma los interrogantes clave que suscita desde una perspectiva antropológica, de un lado, y decolonial sobre el patrimonio, de otro lado. Así, con la caza como caso notorio, el alumnado coautor de este trabajo desarrolló una forma alternativa de presentación de un material didáctico que supone una clara innovación en la enseñanza universitaria sobre patrimonio: se pretendió acercar el tema de una forma dinámica, basada en los métodos de la pedagogía teatral, que se aproximaba a los grandes argumentos dicotómicos sobre la caza tanto desde lo cotidiano como desde lo académico, transformando los argumentos teóricos en argumentaciones sencillas, mixturándose lo coloquial con lo científico y hasta filosófico.

Siguiendo la orientación general de ahondar en la potenciación del conocimiento del patrimonio, tanto en ámbitos escolares como sociales en general, consideramos que esta experiencia de exposición teatral en aula como pretexto para una discusión de fondo antropológico vinculada a los procesos de patrimonialización inmaterial más contemporáneos, debe ser reconocida y explotada por sus fructíferas posibilidades heurísticas en este y otros ámbitos, dadas sus transversalidad, creatividad e interdisciplinariedad metodológica.

\section{Patrimonio y antropología hoy: el patrimonio ¿vivo?}

"El viajero viajó por su país. Esto significa que viajó por dentro de sí mismo, por la cultura que lo formó y está formando, significa que fue, durante muchas semanas, un espejo que refleja imágenes exteriores, una vidriera transparente que luces y sombras atravesaron, una placa sensible que registró, en tránsito y proceso, las impresiones, las voces, el murmullo infinito de un pueblo" (Saramago, 2004: 5).

Antes de continuar en el siguiente epígrafe con el motivo esencial de este artículo, recién descrito, deseamos exponer las perspectivas y las preguntas básicas desde donde nos ubicamos para tratar el patrimonio; dicho de otro modo, desde donde interrogamos a la noción de patrimonio, como profesionales de la antropología ${ }^{4}$, y como fue en consecuencia esta temática abordada durante nuestra asignatura. Así, como en tantos otros temas, la antropología cuando ha mirado el patrimonio se ha preguntado del modo específico que su tradición disciplinaria invoca: ¿por qué el patrimonio? ¿Por qué conservar o salvaguardar, y quién conserva y salvaguarda? ¿Financiado por quién o qué? ¿Qué relativismo cultural hemos de aplicar - si es el caso- para valorar el valor y el sentido patrimoniales? No se trata de que la antropología ensaye siempre una epistemología de la sospecha, pero sí se pregunta siempre quién está detrás (o debajo), y quién todavía más detrás (o debajo). A fin de cuentas, eso ha motivado teorías y enfoques como la interseccionalidad, el feminismo negro o los estudios poscoloniales.

En la sola definición oficial del patrimonio inmaterial de la UNESCO, ya nos topamos de bruces con algunos problemas epistemológicos para la antropología: "Tradiciones o expresiones vivas heredadas de nuestros antepasados y transmitidas a nuestros descendientes, como tradiciones orales, artes del espectáculo, usos sociales, rituales, actos festivos, conoci-

4 Como precisa Mignolo (2010: 17): "no somos porque pensamos sino donde pensamos". 
mientos y prácticas relativos a la naturaleza y el universo, o saberes y técnicas tradicionales de fabricación de objetos artesanales". La noción de tradición, por ejemplo, ha sido ampliamente revisada y contestada en la antropología, hasta el punto de que hoy se concibe como una invención constante (Hobsbawm y Ranger 2012) (no entramos a debatir otros términos como "naturaleza" o "universo" en la definición UNESCO). Así, también el patrimonio va a ser concebido como una recreación constante de una invención o incluso una producción metacultural (Kirshenblatt-Gimblett, 2004 y Martí, 2005); un producto que requiere trabajo para existir, en definitiva.

Así, si bien no se agota en ello, la antropología posee un campo de especial interés en lo que hoy se considera patrimonio inmaterial, intangible o vivo, ámbito en el que se ubica la discusión sobre caza y patrimonialización. El patrimonio inmaterial constituye un claro reflejo de ciertos términos clave de nuestra era: diversidad cultural, altermundialismo, desarrollo... En él sucede una relación metafórica (incluso metonímica) entre patrimonio y cultura (Pereiro Pérez, 2012), y no va a ser solo la cultura erudita o hegemónica la que ahora va a importar sino, muy especialmente, las culturas denominadas subalternas (Senent de Frutos, 2012), las epistemologías hasta ahora silenciadas, vinculado todo ello a la esencial función de salvaguarda cultural que pretende fomentar la UNESCO con los reconocimientos patrimoniales.

Ello supone el giro decolonial en el patrimonio. Si las versiones más conservadoras o decimonónicas del patrimonio buscaban rubricar un "pasado grandioso", las más contemporáneas intentar instrumentalizarlo por los derechos humanos y la democracia. "Para Berenguer la patria era pasado y protocolos. Para Dalmau, derechos y futuro", afirma Sánchez Piñol (2013: 303) en Victus; pues bien, si sustituimos la palabra "patria" por "patrimonio" (ciertamente cercanas en lo etimológico), tendremos una asombrosa descripción de esta realidad.

Ya con la formulación de este "tipo especial de patrimonio" nos topamos con ciertos problemas semánticos (González Alcantud -2012- habla del malabarismo conceptual de las políticas culturales). El término "intangible (mal traducido del original homónimo francés "intangible", que significa que no debe tocarse, no que no pueda tocarse) parece reducir el campo semántico de lo que estamos refiriendo, ya que en castellano solo hace referencia a un sentido, el del tacto. Por otro lado, a menudo hay patrimonios "intangibles" que sí pueden tocarse. "Inmaterial" pareciera algo más amplio pero tal vez también impreciso: todo es material o tiene una base material. (Por otro lado, intentar a estas alturas de filosofía occidental distinguir entre la matera y la no materia nos impelería al campo de la física cuántica, y tampoco queremos eso).

Frente a las anteriores, la denominación frecuente de patrimonio "vivo" resulta, a nuestro entender, formidable y fresca, porque da cuenta con elocuencia y sencillez de la condición eminentemente presente y productiva del patrimonio: no es algo "pasado" que queremos "conservar" sino algo que existe, que reinventamos y revivimos, y que deseamos seguir experimentando, siempre en presente. Finalmente, como precisa Le Scouarnec (en González Alcantud, 2012: 109-110): "Las relaciones entre varias dimensiones de los patrimonios material e inmaterial, entre artefacto y mentefacto, entre contenido y soporte, entre acontecimiento y contexto físico y social explican en parte la inmensa fluidez conceptual que caracteriza el patrimonio cultural inmaterial.

En definitiva, reflexionamos sobre el patrimonio vivo (intangible, inmaterial) desde su perspectiva de "producción metacultural", con Kirshenblatt-Gimblett (2004). Es así como nos planteamos interrogantes sobre la patrimonialización en relación a la caza. Y allá vamos. 


\section{Ejemplo práctico de caza y patrimonialización}

"En nuestra actual sociedad globalizada del siglo XXI la práctica de la caza sigue estando vigente. Lejos ya de sus históricas funcionalidades, hoy la caza entra en intersección con distintos intereses como puedan ser economía, deporte, medio ambiente, turismo, ocio, relación social, identidad o tradición" (presentación de la invitación al coloquio "Caza: ¿deporte, economía o tradición?”, celebrado recientemente por la Asociación Cordobesa de Antropología el 10 de abril de 2014).

\subsection{La idea: innovación pedagógica en acción}

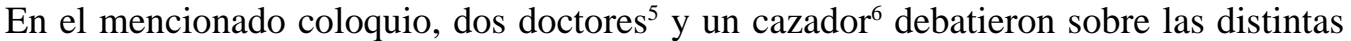
motivaciones que en la actualidad llevan a la práctica de la caza. La caza está de moda, al menos en ciertos sectores, al menos a la par que el vegetarianismo New Age o la terapia craneosacral. ¿Por qué? ¿Qué de interesante antropológicamente hallamos en esto? ¿Y en su vinculación a los procesos de patrimonialización, que ha ocupado algunas de las más recientes investigaciones etnográficas ${ }^{7}$ en nuestro país?

Y, finalmente, ¿cómo transmitir pedagógicamente todo ello en un aula universitaria?

Como al inicio se indicó, durante la asignatura "Patrimonio y Gestión Cultural" (obligatoria del segundo curso del Grado de Antropología Social y Cultural de la Universidad de Granada), la profesora Ester Massó Guijarro ofreció un repertorio de diferentes temas y ámbitos susceptibles de ser tratados en las prácticas por grupos de alumnado; temas que oscilaban del flamenco como patrimonio inmaterial a la Alhambra como patrimonio artístico granadino, pasando por el catarismo como reinvención cultural del Pirineo o el agua como patrimonio natural global en disputa.

De todo ese elenco, la caza era uno de los más controvertidos; la cuestión de la caza que, por otro lado, se revela sin duda primordial para el entendimiento de la antropología social y cultural; ya sea en el ámbito de la evolución humana o de la organización social de los cazadores- recolectores, la caza juega un papel central en la vertebración de los pueblos prístinos. Sin embargo en la actualidad esta actividad goza de muy poco interés académico, al menos entre el alumnado "de a pie" en las aulas universitarias, o la vanguardia, dicho de otro modo; incluso podríamos resaltar un cierto rechazo por parte de los estudiantes de antropología (de la UGR al menos, aunque muy plausiblemente también de otras universidades) ya que muchos de sus perfiles son abiertamente vegetarianos. Sabiendo el poco interés que esta práctica suscita en dicha idiosincrasia más o menos generalizada, fue este tema el que, sorpresivamente, escogió uno de los grupos, precisamente alimentado por el grado de desafío y previsible controversia que presentaba.

Así las cosas, la elección de formato resultaba primordial para una correcta transmisión de la información. La academia se ha acostumbrado demasiado a las exposiciones "por diapositiva", generalmente poco valoradas y rápidamente olvidadas. El formato del Power Point resulta tan sobresaturado que incita al desinterés antes siquiera de comenzar la exposición propiamente dicha. Como estudiantes, valoramos a los docentes que incorporan técnicas dinámicas a sus clases. El conocimiento no resulta más banal ni menos válido si se

5 Manuel Guillén Del Castillo: Doctor y Licenciado en Medicina y Cirugía, Licenciado y Diplomado en Educación Física y Director del Centro de Estudios Olímpicos de la Universidad de Córdoba. Francisco Beltrán Cebrián: Cazador, Director de la web www.cazaymedioambiente.com y presidente del Aula Cinegética del Real Círculo de la Amistad de Córdoba.

6 Antonio González López: Doctor en Antropología Social y Cultural y miembro fundador de la Asociación Cordobesa de Antropología.

7 Como por ejemplo los estudios de González López (2013) o Sánchez Garrido (2006), que de hecho fueron los textos de referencia para la realización de esta práctica en la mencionada asignatura. 
le incorporan elementos tales como el humor o la expresión corporal. Al contrario, al vivirlo diariamente en nuestras carnes, agradecemos la innovación pedagógica como un recurso de extraordinario valor.

Nuestra elección para esta transmisión de información sobre la caza fue el teatro, el formato de expresión teatral, ya que implica la máxima vertebración entre el qué decir y el cómo decirlo. Trabajamos intensamente los textos de referencia, con la esperanza de poder suscitar el interés de nuestros compañeros. Como soporte, decidimos utilizar la imagen, partir de lo concreto para abordar el amplio debate de la caza como patrimonio inmaterial. Para ello, escenificamos a dos personajes (un matrimonio burgués y bastante esnob, en realidad) paseando por un museo ficticio y comentando los cuadros o imágenes que iban encontrando, todos ellos relacionados con la temática de estudio. A través del diálogo, al más puro estilo socrático, abordamos cuestiones evolutivas, de género, de estratificación social, de ocio, de percepciones, de relativismo, a fin de cuentas, de la más pura antropología. El qué decir y el cómo decir.

Cada personaje encarnaba el resumen o el epítome de cada una de las dos grandes posturas ideológicas en torno a la caza (prescindiendo en este caso de posibles matices intermedios en aras de la fuerza expresiva), a saber: la postura abiertamente favorable y la postura decididamente crítica. Así, el marido era el gran defensor de la caza, esgrimiendo típicos argumentos culturalistas, emotivistas, estéticos, históricos, etc., mientras que la esposa (nos inclinamos por la cuestión de género a la hora de escoger que fuera ella la crítica feminista) hacía valer el paradigmático arsenal de argumentos ideológicos contrarios, desde la ética animalista (que él ridiculiza) al cuestionamiento de la naturaleza y el instinto aplicados a la psique humana; hasta la revisión, incluso, de los roles de género típicos en torno a la caza, que han reproducido la subordinación femenina en una división del trabajo nada inocente.

Todo ello, además, se presenta a través del humor, un humor ácido pero fresco, que juega constantemente con la ironía, sarcasmo en ocasiones. En suma, ambos personajes funcionan como arquetipos o antagonistas ideológicos que encarnan, a través de un diálogo que se pretende mayéutico por su fin claramente docente en la práctica de clase, las dos grandes tipologías de argumentos a favor y en contra de la caza, argumentos enraizados en el género o en la ecología o en la sostenibilidad o en el más puro esnobismo.

Como valores transversales, el chisposo diálogo que establece la pareja refleja también el desprecio y la falta de entendimiento mutuo que suele suceder en este tipo de enconados debates ideológicos, en ámbitos tanto populares como académicos, donde parece que lo que importa es "tener razón" a ultranza, y no la búsqueda de algún tipo de verdad consensuada. A continuación exponemos el texto íntegro del diálogo teatralizado representado en clase.

\subsection{Diálogo teatralizado: “¿Y qué pasó con Flor y Tambor?”}

Autores: Pablo Mondragón y Ana Santangelo. Cabecera: http://youtu.be/rlYOblWwQQ4

Introducción: Estimado público: van ustedes a tener el privilegio de asistir al ensayo general de la obra "Y qué pasó con flor y tambor", basada en los trabajos de Roberto Sánchez Garrido ${ }^{8}$. Las opiniones aquí expuestas no corresponden con la de los actores. Rogamos estén atentos y apaguen sus teléfonos móviles. Muchas gracias.

\footnotetext{
8 NOTA IMPORTANTE: Nos referimos especialmente a su artículo reflejado en la bibliografía. Se debe aclarar que lo que sigue constituye una recreación y una interpretación estrictamente nuestras (discrecionales, por tanto) a raíz de la información y el conocimiento ofrecido por Sánchez Garrido en su obra. Este texto, así, está salpicado de referencias suyas y construido en torno a ellas, pero su uso es discrecional y adaptado a los objetivos de la presentación teatral. Aprovechamos para reconocer el estupendo trabajo realizado por este autor, que nos ha permitido la construcción que sigue.
} 
En escena, dos esnobs leen el periódico.

ANA: ¡Desde luego, la gente ya pretende llamar cultura a todo! PABLO: ¿A qué te refieres querida?

ANA: Fíjate en esta noticia, firma un tal Doctor Roberto Sánchez Garrido: "Desde hace unos meses han aparecido en distintos medios de comunicación la iniciativa que la Oficina Nacional de Caza ha planteado al Ministerio de Educación, Cultura y Deporte para presentar a la UNESCO la candidatura de la "Caza" como Patrimonio Cultural Inmaterial de la Humanidad". PABLO: (indiferente) ¿Y de qué te extrañas querida? Como todo, la patrimonialización responde a unos intereses económicos concretos de un grupo de presión concreto, que pretende utilizar los avatares de la conservación y el legado cultural para engordar sus bolsillos. Si la evolución acabase con el dedo meñique de mi pie, algún listillo pagaría por verloen un museo.

ANA: ¡De igual modo, es un tema de soberbia importancia! Convertir la muerte en legado de la humanidad, iponer las vísceras de un carnero al nivel de la Gioconda! ¡Es inaudito!

PABLO: Aún con todo, me resulta un tema de importancia superflua. Quizás algún hediondo bohemio indigenista cuyo onanismo ecológico patrocine las arcas de Greenpeace vea en dicha noticia algún trazo de autoestima combativa que rascar, pero gente de mundo como tú y como yo, personas que entienden la cabalidad de la cadena alimenticia... pierden el tiempo con este tipo de conversaciones.

ANA: Tu actitud solo es un reflejo de tu ignorancia, querido. Creo que tantas horas en el estudio te están haciendo perder la noción de la realidad, y que tu egocentrismo narcisista solo es una disfunción de una etapa fálica no superada. ¿Es que acaso no está castrado Sr. Edipo?

PABLO: Tocado, pero no hundido. Muy bien, puesto que hoy es el día internacional de las sandeces, te reto a encontrar al menor interesado en dicho tema. La caza como patrimonio. ¡Y a quién le importa!

ANA: Por Dios, (grita) ¿A alguien le importa que la caza se patrimonialice? (Susurrando) ¿Alguien cree que mi esposo es un completo idiota?

PÚBLICO: ¡Sííííí!

ANA: $;$ Ya puedes ir a llorar a una esquina, querido!

PABLO: Por estas cosas la democracia nunca será un buen sistema. De acuerdo

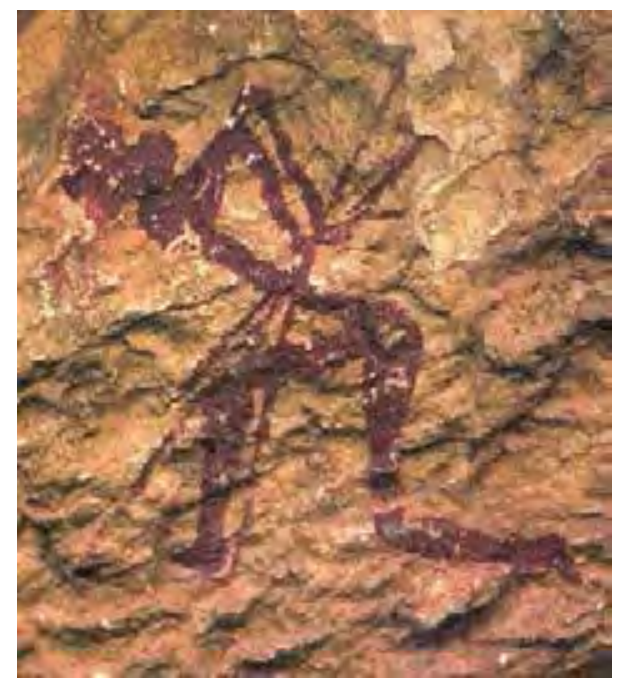


ma chérie, hablemos de caza, pero espero que este irrelevante contratiempo no sacrifique nuestra hora de lectura silenciosa. ¡Paseemos!

PABLO: Mmmmm...

ANA: ¿Qué poco glamour, esposo mío! Traerme a Albocasser (acento valenciano cerrado) en vez de Altamira.

PABLO:Amítampocomehaceningunagracia,querida.Estamosenlacosta, asíque sobretodo vigila tu cartera. ¿Quién sabe quéclase de constructor podría asaltarnos! ANA: (poniendo su bolso delante) ¿Es esto lo que pretendías enseñarme? ¿Un grafitti en una roca?

PABLO: Soy consciente de que tu capacidad para conectar conceptos es inversamente proporcional a tu capacidad para gimotear, pero aunque no lo creas, esta es una escena de caza. Te encuentras ante el mayor exponente del arte rupestre levantino. ¡He aquí el reflejo de las verdaderas preocupaciones del ser humano! (señalando) ¡El sustento... y la mujer!

ANA: Querido, veo que no estás familiarizado con el test de Rorschach. Que la proyección de tu ego te haga ver instrumentos de muerte con forma fálica en manos de una mujer no significa que tu perspectiva vaya acorde con la... realidad empírica (gesto de pequeño hacia el público).

PABLO: (serio) Muy ingeniosa querida, chistes de penes, recuérdame que te envíe una carcajada por correo certificado.

ANA: (indiferente, coge el prospecto) ¿Y qué pretendes demostrarme querido? ¿Que la caza es una actividad milenaria? ¿Vas a hablarme de la importancia de la proteína animal para el desarrollo cerebral de nuestros antepasados? ¿O quizás dramatices exaltando esa idea de hombre solitario, rastreando el monte en busca de señales que visualicen lo invisible, la idea del hombre integrado en la naturaleza como el buen salvaje rousseauniano?

PABLO: Imagino que la clase sobre cazadores/recolectores te sorprendería en alguna terapia de grupo para herbívoros. ¿No estás familiarizada con los San de Namibia? Aún existen numerosos grupos cuya forma de sustento depende intrínsecamente de la caza. ¿Sería preferible instalar un matadero industrial al lado de sus poblados y abrir una sucursal de Mercadona? Desde los inicios de la humanidad, el hombre ha utilizado los recursos animales que tenía a su disposición, tanto por alimento como por abrigo. Dudo mucho que un Neandertal tuviese el menor reparo moral en matar un ciervo, pero claro, para nosotros él es un atrasado.

ANA: ¿Y no lo son? Se extinguieron hace 20.000 años. No fue precisamente ayer. Y desde entonces, la ciencia ha desarrollado materiales sintéticos, durables, capaces de sustituir a las pieles, del mismo modo que podemos nutrirnos sin necesidad de consumir animales. ¿O acaso crees que un filete de carne, cruda por cierto, es beneficioso para tu organismo?

PABLO: No considero que debamos convertir este debate en charlatanería dietética. Nos encontramos ante una pintura rupestre, una representación de los modos y costumbres de una época donde ni el nylon ni el tofu eran hegemónicos en los valores de un colectivo. Lo era el cazar. Y por cierto, no solo hablamos de sustento y de abrigo. Piensa en las primeras formas de comunicación, de estrategia, de sociabilización, todas derivadas de una necesidad de obtener proteínas animales. ¡Devorando animales! Ahí tienes a los parantropus. Su destino fue trágico. ANA: Si quieres, cuando termines tu discurso primitivista, podemos pasar al siguiente cuadro. Dejémoslo en que es una mujer con muletas.

PABLO: Me parece correcto. 


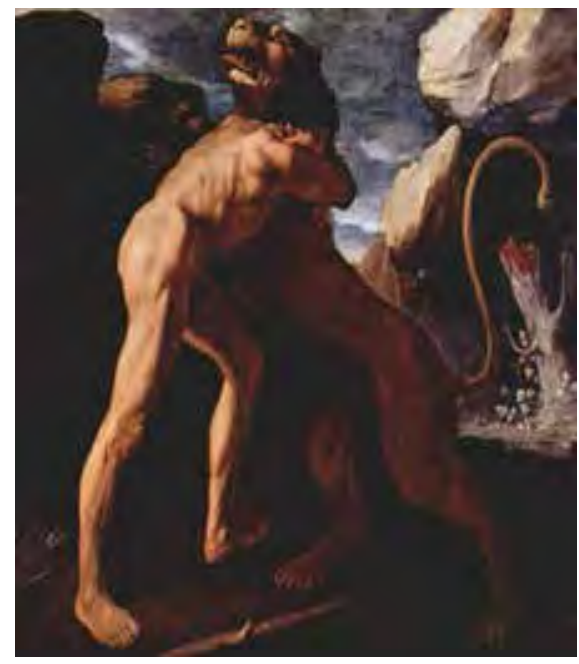

ANA: Este lo conozco. Es Hércules purgándose del asesinato de su esposa Megara, realizando el primero de sus doce trabajos. Aquí debía abatir al León de Nemea.

PABLO: ¡Exacto! El León atemorizaba a los habitantes de la aldea, y el héroe Heracles persiguió a la bestia desde Grecia hasta la punta de Finisterre. El héroe, Ana. El héroe es la figura por antonomasia de todas las culturas, iy todos los héroes cazan! Sigfrido era un experimentado cazador, del mismo modo que lo era Noe, y Mahomma. Nuestros ideales, nuestro imaginario colectivo, toleran y agradecen la caza. Es la medición del hombre contra la bestia, la clásica dicotomía entre cultura y naturaleza.

ANA: Por supuesto. No hace falta que me convenzas que a la figura del hombre se le asumen una serie de atributos que representan su masculinidad...

PABLO: „Como dijo Bourdieu: "Los hombres son los encargados de realizar los actos "breves, peligrosos y espectaculares"!

ANA: Cuando termines contigo mismo, seguimos hablando.

PABLO: Quería evitar una cascada de lloriqueos feministas. Pero bueno, sigue. ANA: ¡Idiota! ¿No ves que es obvio que lo masculino y lo femenino son roles ya determinados desde la infancia? A nosotras ni siquiera nos ofrecen ir a cazar. Siempre es al varón al que enseñan. Ese niño, como varón, se supone preparado para la rudeza, para la sangre, mientras que a la niña se le compran cocinas y muñecas. Pensamos que este discurso está superado, pero nada más lejos de la realidad. A la mujer no se le socializa en este ambiente al no considerar este como su lugar.

PABLO: No conozco casos de mujeres no admitidas en cacerías.

ANA: ¡Obvio! No hace falta ejercer una discriminación posterior. Ya viene dada desde la temprana infancia. La mujer no tiene ningún interés en salir a cazar. No es lo que le han enseñado. La mujer participa en los elementos, pero siempre desde otra perspectiva. Son las esposas de los cazadores las que avían la pieza, ellas matan a las aves de corral. No es el acto de matar en una cacería, sino la construcción, la identidad que de él emerge, la que aparta a la mujer de la caza.

PABLO: Tengo un amigo que estaba deseoso de salir a cazar por el simple hecho de alejarse de su "vida cotidiana", que es otra manera de llamar a su mujer. Es lógico. Sale de casa, forma identidad de grupo con sus compañeros, 


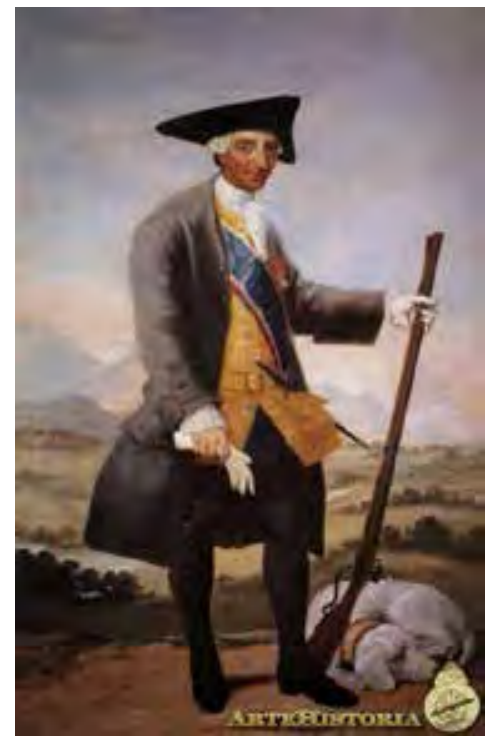

hablan de sexo, están hasta mediodía, o hasta la noche y se olvidan de todo. ANA: Lo que tu llamas sociabilización, yo lo llamo relaciones de poder. Y no solo del hombre hacia la mujer, sino que en su estúpido afán por matar una pieza, el hombre pretende también dominar la naturaleza.

PABLO: ¿No estarás generalizando?

ANA: ¡Por favor! Los dos sabemos que ese cazador tradicional, ese entrañable hombre que intenta adaptarse a la naturaleza para conseguir la pieza, es una especie en extinción.

PABLO: ¡No te adelantes! Sigamos paseando.

ANA: ¡Hostia qué feo!

PABLO: Carlos III. Como bien has dicho, era un tipo muy feo. Goya retraba tal cual era la monarquía. Endogámica y muy antiestética. Un poco como ahora. ¿Verdad, Goya?

GOYA: ¡Sí!

PABLO: ¡Gracias, Goya! Y además querida, era cazador. Un pobre ilustrado, feo, que solo quería pegar tiros.

ANA: Es a esto exactamente a lo que refería. Gente que no es genuinamente de campo, gente que no es auténtica. No conocen los terrenos, no conocen los acordes vitales de la naturaleza. ¡Vienen de una selva de hormigón! ¿Qué van a saber?

PABLO: ¡Que original! La clásica dicotomía entre campo y ciudad. El hecho de venir de campo o de ciudad es independiente al conocimiento de la naturaleza. De hecho, sin teoría, sin una visión completa de la actividad, todo el conocimiento queda sesgado. Es importante estudiar antes de ejercer, mucho más antes de matar.

ANA: ¿Qué me dices de la experiencia? No estamos hablando de Derecho, ni de pasarse horas empollando montañas de apuntes, sino de salir a cazar. Pensar qué vas a cazar, cómo lo vas a cazar y donde lo vas a cazar son ámbitos donde prima la experiencia.

PABLO: Ya hemos tenido esta conversación varias veces y no lleva a ningún punto. Retomando la autenticidad.

ANA: Pues es el antagónico del cazador de Madrid, que equipado de los pies a 


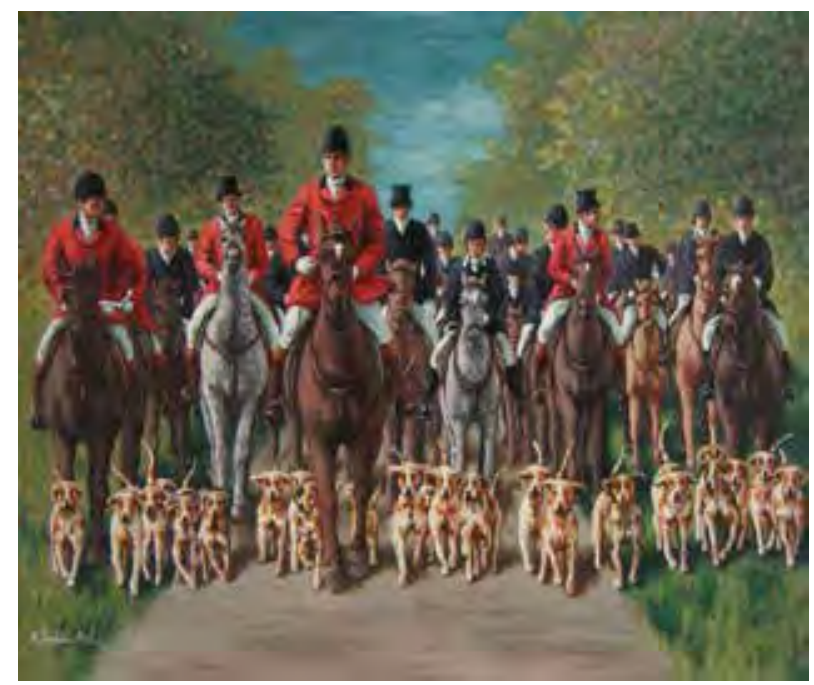

la cabeza de instrumentos de caza, seguido de dos podencos y dos galgos, sale al amanecer del domingo por la puerta de Atocha, con su hermosa escopeta debajo del brazo y su gorra de visera reluciente, asusta a los gorriones de la pradera del Canal y se vuelve molido y sudado al anochecer, después de haber tenido que comprar algún conejo y una caña de alondras.

PABLO: Eso es de Larra.

ANA: ¿Y? Parece que si no proviene de la academia no escuchas. El caso es que esos escopeteros se caracterizan por un afán desmedido por matar. Matar, matar y matar. Ni cumplen las normas medioambientales, les da igual una presa o un elefante atado frente a ellos. Siempre dispararán. En lo auténtico, lo determinante es la actitud, la percepción que se tiene del bosque y su integración en el mismo. Cazar no es matar. La caza no es algo puntual, sino que es una parte de ellos.

PABLO: ¡Uh, acabo de estremecerme! Viva Ortega y Gasset. Pero no olvides que estás omitiendo un punto de vista. La caza puntual y recreativa, la de los

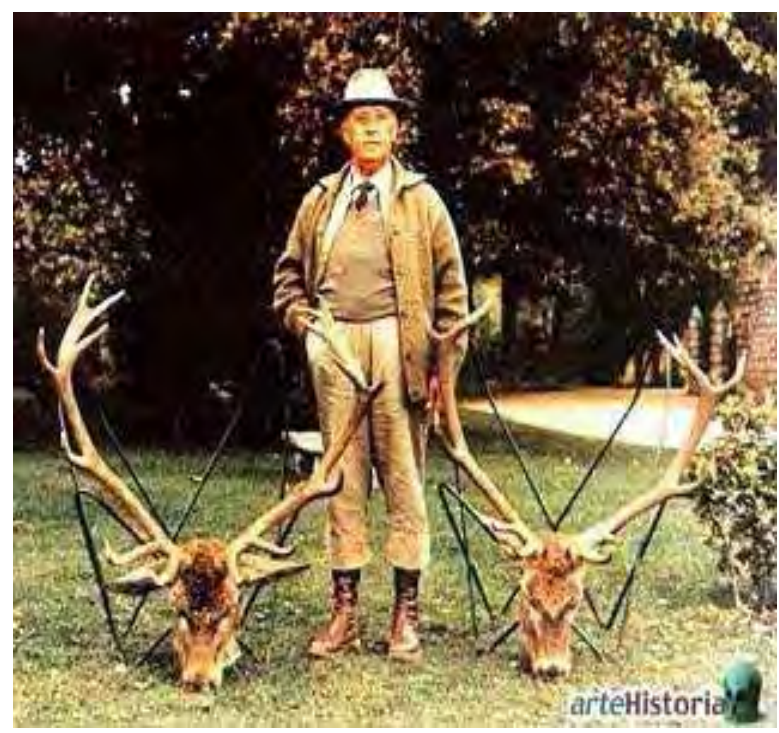


cotos y los domingos, es lo que ha mantenido viva la actividad cinegética. Si los forrados de Madrid no salieran a pegar tiros de vez en cuando, tus pobrecitos del campo estarían en prisión.

ANA: Aunque seas un verdadero imbécil... ¡Por fin coincidimos en algo! Elitismo... (gesto soberbio con la mano.

ANA: Vaya... ¿tú sabes algo de la caza del zorro?

PABLO: No tengo la menor idea.

ANA: Pues sigamos, porque yo tampoco.

PABLO: ¡Mira quién tenemos aquí! ¡El Generalísimo!

ANA: Sí, Franco posando con una par de cabezas muertas. Es el clásico ejemplo de la decadencia que viene sufriendo la caza. Ricos y poderosos se codean bailando encima de las vísceras de los animales, mientras encienden sus puros y se felicitan por ser los amos del mundo. PABLO: Siempre lo he dicho. La economía del país se decide en bares, prostíbulos y cotos de caza. Esto es como la película esa en la que un fabricante de porteros automáticos, de esos del timbre, organiza una cacería para vendérselos al ministro en el coto de un Marqués y...

ANA:¡Ah sí! "La escopeta nacional”. ¡Qué buena es!

PABLO: ¡Ya ves, está tó guapa.

CAROLINA: (carraspea).

PABLO: Mmmm... lo que quería decir es que Berlanga supo reflejar muy bien las relaciones comerciales que se ejercen en esas esferas. Empresarios, ministros, nobleza. Todos ellos creyéndose gente de monte.

ANA: ¡Además, eso no es caza! Y es justamente la imagen que se transmite a la sociedad. Un llamado deporte que no es más que la satisfacción de unas élites con objetivos concretos. Una práctica de poderosos.

PABLO: Pues entonces esto te va a encantar.

ANA: Oye, ¿tú sabes que el rey mató a su hermano?

PABLO: ¿Cómo?

ANA: Se le disparó una escopeta de caza.

PABLO: ¿Era el mayor?

ANA: Sí.

PABLO: ¿El futuro heredero?

ANA: Sí.

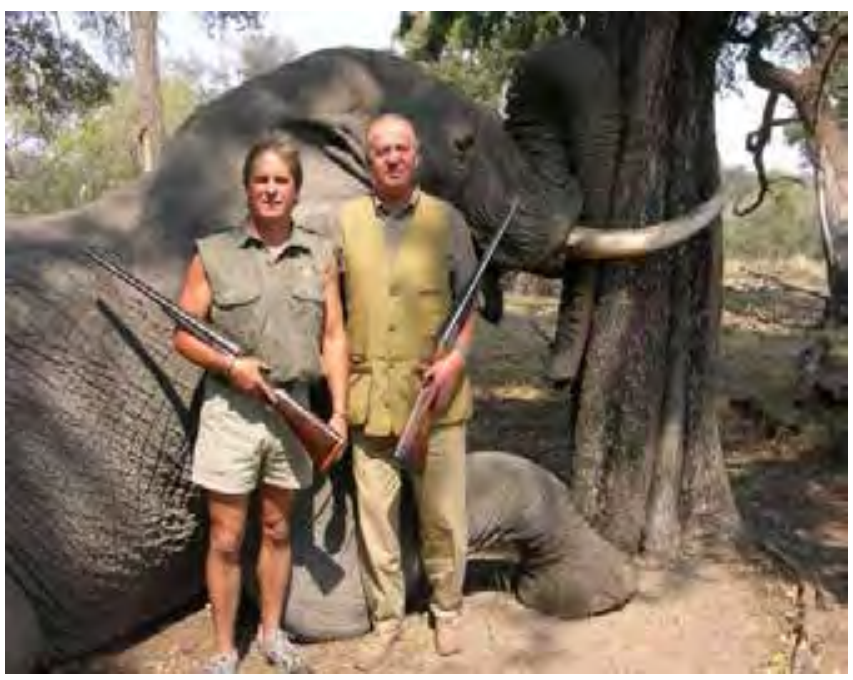


PABLO: Armas y endogamia nunca fueron buenas amigas. (silencio).

ANA: Es que no lo entiendo. ¿Por qué elefantes? Ni siquiera te lo comes.

PABLO: Volvemos a lo mismo de antes. El hombre domina a la naturaleza. El hombre se embarca en gestas contra animales mucho más grandes que él, iy eso vende! Los ricos pagan millonadas por tener unos colmillos en su salón de estar. Se creen Hércules frente al león de Nemea, se creen el bosquimano que corretea por la sabana, el valeroso aventurero que con su razón y estrategia domina las tierras salvajes y somete a sus habitantes. Pero tan solo son desgraciados con municiones muy caras. Pack turístico: ¡Viaje a Botswana, mate un León y cómase una cebra! Muerte, muerte, muerte, muerte para ensalzar su hombría. ¿Qué ha sido del cazador y su escopeta? ¿Qué del perro y su reclamo? Han pasado como lluvia en las montañas. Como viento en la pradera. Los días se apagan para la caza, tras las colinas. Sumida en la sombra... ¿Cómo hemos llegado a esto? (silencio).

ANA: ¿El nieto de este no se pegó un tiro en el pie?

PABLO: Estoy aburrido.

ANA: ¿Nos vamos?

PABLO: ¿Y el público?

ANA: Pfff.

PABLO: ¿Cine?

ANA: Vale.

\section{Reflexiones finales}

El objetivo principal de este texto ha sido eminentemente práctico: mostrar un ejemplo de innovación pedagógica en la docencia universitaria vinculada a conocimientos de antropología, concretamente el patrimonio vivo y con el caso específico de la caza. Partimos de una comprensión crítica (poscolonial) de la antropología en relación al patrimonio, de un lado, y de la caza como una forma controvertida de patrimonio inmaterial o vivo. Finalmente, de ahí desembocamos a la forma en sí de transmitirlo, como práctica, en un aula universitaria de antropología: la forma de diálogo teatral o teatralizado.

Este formato (que produjo el texto que recién se ha leído íntegramente y que supone, en realidad, una pequeña obra de teatro) cumplió su cometido original, suscitando un interés en el aula y un debate claramente superiores los que habría logrado un formato tradicional de monólogo expositivo. Sin perjuicio de la transmisión de conocimientos y datos concretos, que fue lograda con brillantez, se acercó la temática de la caza a un auditorio discente, como decíamos, con gran número de vegetarianos y veganos, por ejemplo, o personas concernidas por éticas animalistas de diversa índole; personas que aprendieron y debatieron animadamente aunque fuera, en muchos casos, por oposición: a través del disenso avanzamos en el conocimiento dialogado de una singular manera.

\section{Bibliografía}

CHOAY, Françoise (2009) Le patrimoine en questions. Anthologie pour un combat. París: Editions Du Seuil.

GONZÁLEZ ALCANTUD, José Antonio (2003) Patrimonio y pluralidad. Nuevas direcciones en antropología patrimonial. Granada: Centro de Investigaciones Etnológicas Ángel Ganivet.

GONZÁLEZ ALCANTUD, José Antonio (2012) El malestar en la cultura patrimonial. La otra memoria global. Barcelona: Anthropos.

GONZÁLEZ LÓPEZ, Antonio (2013) "Procesos de patrimonialización en el mundo de la caza". 
Revista de Antropología Experimental, 13: 255-266.

HOBSBAWM, Eric y RANGER, Terence (eds.) (2012) La invención de la tradición. Barcelona: Crítica.

KIRSHENBLATT-GIMBLETT, Barbara (2004) "Intangible heritage as metacultural production". Museum International, 221-222-56: 52-65.

MARTÍ, Gil-Manuel (ed) (2005) La memoria construida. Patrimonio cultural y modernidad. Valencia: Tirant lo Blanch: 192-223.

MIGNOLO, Walter (2010) Desobediencia epistémica. Buenos Aires: Ediciones del Signo.

PEREIRO PÉREZ, Xerardo (2012) "La concepción del patrimonio etnoantropológico en Galicia: visiones legales y prácticas institucionales". Revista Andaluza de Antropología, 2 (sin paginación en versión electrónica).

PRATS, Llorenç (2004) Antropología y patrimonio. Barcelona: Ariel Antropología.

SÁNCHEZ GARRIDO, Roberto (2006) "De caza y cazadores. Las construcciones teóricas sobre la actividad cinegética actual a partir de los discursos de sus actores". Gazeta de Antropología, 22.

SÁNCHEZ PIÑOL, Albert (2013) Victus. Barcelona 1714. Barcelona, La Campana.

SARAMAGO, José (2004) Viaje a Portugal. Barcelona: Santillana.

SENENT DE FRUTOS, Juan Antonio (2012) "Derechos humanos, derecho a la cultura y pueblos indígenas". Revista Andaluza de Antropología, 2 (sin paginación en versión electrónica). 